\title{
Assessing desertiñcation risk using system stability condition analysis
}

\author{
Javier Ibáñez, Jaime Martínez Valderrama, Juan Puigdefábregas \\ Dpto. Estadística y Métodos de Gestión en Agricultura, Universidad Politécnica de Madrid, Spain \\ Estación Experimental de Zonas Áridas, Consejo Superior de Investigaciones Científicas, Spain
}

A B S T R A C T

Keywords:

Desertification risk

System Dynamics

Alternative long-term states

\begin{abstract}
This paper describes a procedure for evaluating the desertiñcation risk in threatened áreas. The procedure is based on an eight-equation dynamic model of a generic human-resource system that can be applied to different desertiñcation syndromes. For each application, interest focuses on finding all the possible long-term final states of the system and on defining the conditions that mark out sustainability and long-term desertification by means of unambiguous specific parameter relations. The procedure is applied to three typified cases in Spain: (A) rainfed crops in áreas with high soil erosión risk; (B) irrigated intensive agricultural systems; and (C) commercial rangelands. Results show that, in case A, high profit scenarios are responsible for the final extensión of desertification but do not determine the specific threshold between sustainability and desertification. They do, however, in cases B and $\mathrm{C}$.
\end{abstract}

\section{Introduction}

Dealing with desertification in threatened áreas requires some assessment capacity to provide guidelines for implementing successful mitigation and monitoring programmes. Such capacity includes identifying symptoms and driving forces and evaluating risk. The approaches to desertification assessment evolved with the desertification concept itself. This was established after the big drought that the Sahel experienced in the 1970s. Desertification was, at that time, associated with the soil's loss of capacity to sustain yield and population. Cumbersome debates took place to ascertain whether humans or climate were causing that process until it was understood that the effect was synergetic.

This conceptual upgrading is expressed in the UNCCD (1998) definition of desertification as 'the land degradation in arid and semi-arid and dry-sub-humid áreas resulting/rom variousfactors, including climatic uariations and human actiuities'. In spite of its generality and simplicity, this definition has the advantage of providing a benchmark for designing assessment and diagnostic methods. The outcome or symptom of desertification is land degradation, and its driving forces are climatic variations and human activities. Furthermore, land degradation is defined by UNCCD (1998) as the 'loss of land's biological and economic productiuity and complexity'. This is a holistic definition that looks at the bulk impact rather than at the particular causes, like soil erosión, salinization, etc.

Later on a more integrated view of desertification as a sustainability loss of the human-renewable resource systems emerged (Puigdefábregas, 1995). This view explicitly accommodated the various linkages between socio-economic and biophysical factors in appropriate spatial and temporal frames (Stafford-Smith and Reynolds, 2002).

The above conceptual evolution can be tracked across three worldwide landmark projects that reveal a historical trend of increasing complexity in desertification assessment approaches (GLASOD, 1990; LADA, 2002; Millennium Assessment, 2005). They upgrade from 'soil' to 'land' degra- 
dation, from only considering effects to explicitly including drivers (climate variability and human activity) and to becoming more concerned with global interactions of desertification (climate change, biodiversity).

Underlying these more complex and integrated assessment concepts is the impact of disturbances on the sustainability of threatened human-resource systems. Most of the reported desertification cases share a common feature. They witnessed disturbances that had not been experienced before in their history (Puigdefabregas, 1998). Some possible examples are strong changes in climate, market conditions and agricultural policies, demographic booms or technological revolutions. The overall effect of these disturbances is to take the threatened systems beyond their resilience thresholds. Sustainability in human-renewable resource systems includes at least economic and ecological thresholds (Pickup and Stafford-Smith, 1993). The former mostly occur earlier than the latter and consequently human populations leave off their pressure on renewable resources. In desertification cases, however, people cannot get out and are forced to continué exploiting resources beyond their ecological resilience threshold un til land degradation is 'irreversible'.

Land degradation is a 'holistic' concept and has often been inadequately assessed by adding up several soil features, such as erosión, compaction, salinization, nutrient depletion, etc. Recently new approaches are being developed. They are based on ecosystem functions such as productivity (Prince, 2002) or efficiency in the use of water (Boer and Puigdefabregas, 2005). The advantage of these methods is that they are based on attributes that can be directly associated with the ecosystem's maturity level. However, they fail to include thresholds and intégrate human activities. While they do work well for monitoring designs, they are not entirely suitable for risk assessment applications.

Lately it has been suggested that the concept of desertification syndrome is the characteristic sets of symptoms that are associated with specific series of disturbances in desertification threatened áreas (Geist, 2005). Desertification syndromes provide a useful frame for integrating the human and biophysical components of household populations or similar management units. They also constitute a qualitative shift from desertification status assessment to risk evaluation.

Desertification risk analysis has been approached by applying system dynamics techniques to various developments of the classical predator-prey ecological models (Puigdefabregas, 1995; Regev et al., 1998). These attempts provide relevant theoretical insights. However, they are not yet applicable to a variety of real cases because of the lack of flexibility forced by the assumption that there are no relations between state variables other than consumption and because of they do not consider the soil subsystem, which plays an overriding role in desertification processes.

This contribution explores an alternative simplified option to desertification risk analysis. It also relies on system dynamics models, but they are more flexible than those mentioned above. Also, it rules out detailed prediction of system trajectories. Instead interest focuses on finding all the possible long-term alternative states of human-resource systems if climatic and economic scenarios are kept constant in their normal or average valúes. In spite of the absence of exoge- nous fluctuations or disturbances, final states of what could be called 'structurally driven' desertification can be predicted, as can the conditions that lead to these states. This is because the system's fate can be expressed in terms of explicit parameter relations. Such conditions are actually unambiguous indicators and thresholds in the risk analysis procedure.

The procedure is flexible and robust enough to be applied to a wide range of desertification syndromes. Results would be more reliable if such applications were to employ widely accepted partial models (e.g., the logistic growth equation of natural populations, profit maximization conditions, the exponential drop in erosión rates with growing vegetation cover), as is the case in the three applications described in this work. Of course, although the use of the model we make here is non-time explicit, it could also be used to analyse transient behaviours under different time-based scenarios.

The proposed approach relies upon a common set of eight dynamic equations, which is described in Section 2. Sections 3-5 apply the generic model to three áreas of Spain typified as threatened by desertification. Equilibrium conditions are analysed and the thresholds marking out sustainability and structural long-term desertification are defined for each of the three applications. Results are discussed in Section 6, which concludes this paper.

\section{A theoretical dynamic human-resource system}

The following generic eight-equation dynamic model is proposed to evalúate structural long-term desertification risk in threatened áreas (capital letters are employed to ñame variables and small letters to denote parameters throughout the paper).

- Eq. (1) Number of consumption units

$\mathrm{U}=$ consumption units; $\mathrm{g}(-)=$ natural growth of $\mathrm{U} ; \mathrm{U}^{\mathrm{D}}=$ target consumption units; uat=adjustment time of consumption units.

The consumption units $\mathrm{U}$ could be, in the simplest case, some human population but also, in more complex cases, entities like hectares, enterprises or livestock herds. The first term in 2.1 , the natural growth rate of $U$, would only be required for the case of modelling a human (i.e. a natural) population. This natural growth could be influenced by the current stocks of both the natural resource $\mathrm{R}$ and the limiting factor $\mathrm{S}$ which are defined bellow. The second term in 2.1, the migratory rate of $\mathrm{U}$, would be useful in any case. When $U^{D}>U$ this term represents the rate of consumption units incoming to the system. When $U^{D}<U$ the term stands for the rate of consumption units leaving off the system. A partial adjustment scheme is assumed for the migratory rate, where uat is the average adjustment time. This could differ depending on whether it refers to consumption units entering or leaving the system. 
Eq. (2) Target consumption units

$$
\mathrm{umxFo}(\mathrm{Pu})
$$

$\mathrm{U}^{\mathrm{D}}=$ target consumption units; umx = máximum number of consumption units; $\mathrm{Pu}=$ profit per consumption unit; $\mathrm{O}=$ opportunity cost in a consumption unit (random variable); Fo(-) = cumulative distribution function of 0 [i.e. $\left.\mathrm{F}_{\mathrm{o}}(\mathrm{Pu})=\operatorname{prob}(0<\mathrm{Pu})\right]$.

On the one hand, we assume that the máximum number of consumption units is constrained to umx because of factors that are exogenous to the model (i.e. geographic or biophysical limitations). On the other, only those units where profit $\mathrm{Pu}$ is greater than opportunity cost 0 should go into the modelled system. The opportunity cost is randomly distributed across the units. This explains why its cumulative distribution function $\mathrm{F}_{0}(-)$ is used in Eq. (2.2).

Eq. (3) Production function

$\mathrm{Qu}=\mathrm{q}(\mathrm{Ku}, \mathrm{Ru}, \mathrm{S})$

$\mathrm{Qu}=$ production per consumption unit; $\mathrm{q}(-)=$ production function; $\mathrm{Ku}=$ capital demand per consumption unit; $\mathrm{Ru}=$ natural resource demand per consumption unit; $\mathrm{S}=$ limiting factor.

The average production per unit $\mathrm{Qu}$ depends on the quantities of capital $\mathrm{Ku}$ and natural resource $\mathrm{Ru}$ employed. However, the existence or accumulation of some limiting factor $\mathrm{S}$ could negatively affect production.

Eq. (4) Profit

$\mathrm{Pu}=\operatorname{prq} \mathrm{Qu}-\mathrm{c}(\mathrm{Ku}, \mathrm{Ru})-m(S)-\mathrm{fcu}$

$\mathrm{Pu}=$ profit per consumption unit; prq = price of production; $\mathrm{Qu}=$ production per consumption unit; $\mathrm{c}(-)=$ variable cost function; $\mathrm{Ku}=$ capital demand per consumption unit; $\mathrm{Ru}=$ natural resource demand per consumption unit; $\mathrm{m}(-)=$ cost of corrective measures of $\mathrm{S} ; \mathrm{S}=$ limiting factor; $\mathrm{fcu}=$ fixed cost per consumption unit.

Average returns per unit are the result of multiplying the product price prq by the average quantity produced Qu (subsidies are ignored although could easily be included). Average profits per unit $\mathrm{Pu}$ are obtained after subtracting variable costs $\mathrm{c}(\mathrm{Ku}, \mathrm{Ru})$, the cost of measures for correcting the effects of the limiting factor $m(S)$ and the fixed cost fcu from returns.

Eq. (5) Capital demand per consumption unit

$\begin{array}{ccccc}\frac{\mathrm{dKu}}{\mathrm{dt}} & \mathrm{Kh} \cdot \mathrm{Ku} & \operatorname{prq~dQu} / \mathrm{dKu} & \text { srk } & \mathrm{Ku} \\ \mathrm{alk} & \mathrm{GK} & & \mathrm{alk}\end{array}$

$\mathrm{Ku}=$ capital demand per consumption unit; $\mathrm{K}^{\wedge}=$ target capital demand per consumption unit; alk =average life of capital; prq = price of production; $\mathrm{Qu}=$ production per consumption unit; GK = marginal cost of capital; srk = sensitivity to relative return to capital.

The first expression for the rate of variation of $\mathrm{Ku}$ is a quite generalized one which seeks to be useful for a wide range of desertification syndromes. The last expression in 2.5 is a special particularization of the first one for those cases where the consumption units opérate within a market's economy. Here we assume that each of the consumption units seeks its own short-term profit maximization, i.e. there is no kind of long-term oriented regulation. Profit maximization is achieved when the value of the marginal product of capital, prq dQu/dKu, is equated with its marginal cost, GK. The consumption units follow a hill-climbing heuristic for such optimization: target demand for capital is anchored to the current demand and varies in the economically expected way from such demand under disequilibrium situations (Sterman, 2000). For example, if the valué of the marginal product of capital were greater than its marginal cost, the target demand $\mathrm{K}^{\circ}$ would turn out to be greater than the current demand $\mathrm{Ku}$. The sensitivity of $\mathrm{K}^{\wedge}$ to changes in the relative return on capital is quantified by the constant srk. Finally, we assume that the average life of capital alk is the average adjustment time for the partial adjustment scheme established between the current and target valúes for capital demand.

- Eq. (6) Natural resource demand per consumption unit

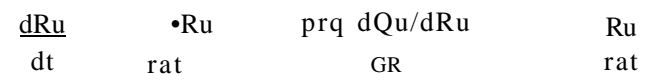

$\mathrm{Ru}=$ natural resource demand per consumption unit; $\mathrm{R}^{\circ}=$ target natural resource demand per consumption unit; rat=adjustment time of natural resource demand; prq = price of production; $\mathrm{Qu}=$ production per consumption unit; $\mathrm{GR}=$ marginal cost of natural resource; $s r r=$ sensitivity to relative return on natural resource.

The assumptions of this equation are similar to the assumptions for Eq. (5). Short-term maximization means here that the natural resource is exploited competitively, i.e. with no agreement concerning such exploitation between the consumption units (Ibáñez et al., 2004).

Eq. (7) Stock of natural resource

$\begin{aligned} & \mathrm{dR} \\ & \mathbf{d F}\end{aligned} \quad \mathrm{r}(\mathrm{R}, \mathrm{S})-\mathrm{URu}$

$\mathrm{R}=$ stock of natural resource; $\mathrm{r}(-)=$ net renewal rate of $\mathrm{R} ; \mathrm{S}=$ limiting factor; $\mathrm{U}=$ consumption units; $\mathrm{Ru}=$ natural resource demand per consumption unit.

The stock of natural resource has a net renewal rate $r(R, S)$ which could be negatively affected by the limiting factor $S$. The rate of depletion is equal to the total demand for the resource, i.e. the product of U times Ru-

Eq. (8) Stock of limiting factor

dS

$\mathrm{dt}$

:s(S, U, Ku, R $)$

$\mathrm{S}=$ limiting factor; $\mathrm{s}(-)=$ net renewal rate of $\mathrm{S}$; $\mathrm{U}=$ consumption units; $\mathrm{Ku}=$ capital demand per consumption unit; $\mathrm{R}=$ stock of natural resource.

The net stocking rate of the limiting factor could, in principie, be related to its current stock, the number of consumption units, the quantity of capital employed in each unit or the stock of natural resource. 
The eight equations explained above form the fundamental framework of a dynamic model for studying desertification. For such a framework to be applied, the functions $\mathrm{g}(-), \mathrm{F}_{0}(-)$, $\mathrm{q}(-), \mathrm{c}(-), \mathrm{m}(-), \mathrm{r}(-)$ and $\mathrm{s}(-)$ will obviously need to be given specific forms and the resulting set of parameters will have to be calibrated. The resulting model could be used to show the expected trajectories of the variables given both some time-based parameter scenarios and the assumed rational behaviour of the consumption units. Additionally, the model could be used to analyse its long-term equilibrium conditions, something that can actually be done before parameter estimation. This is the use that we explore in this paper in order to define explicit structural desertification thresholds.

Specifically, we apply the theoretical system to three desertification syndromes in Spain. These syndromes have been typified by the National Desertification Action Programme (Ministry for the Environment, 2003). They are: (A) rainfed crops in áreas with high soil erosión risk; (B) irrigated intensive agricultural systems; and (C) commercial rangelands. These cases have been sorted in order of increasing complexity.

\section{Case A: rainfed crops in áreas with high soil erosión risk}

In Spain, woody crops (olives, fruit, grapevines) "are frequently si ted on highly or médium sloping lands, with a low planta tion density. These circumstances, plus frequent agricultural work to remove the competitive grass cover, diminish soil's protection against erosión" (Ministry for the Environment, 2003, p. 26). Common Agricultural Policy (CAP) incentives could possibly influence the expansión of woody crops into steeply sloping áreas. Also "sizeable erosion-induced losses of soil occur in áreas of rainfed annual crops on slopes ranging from modérate to high with no soil conservation measures. The cereal/fallow rota tion system leaves the soil stripped of vegetation in autumn when rainfall is heaviest" (Ministry for the Environment, 2003, p. 27). The traditional measures for soil conservation, which cali for a significant labour forcé, have become unprofitable for farmers.

\subsection{Model equations}

The following likely assumptions are adopted in order to represent the typology of case A by means of the model described in Section 2:

Eq. (1A)-Be U in Eq. (2.1) the number of hectares, a type of consumption units for which $\mathrm{g}(-)=0$. In this way:

$$
\begin{array}{rr}
\text { dU } & U^{D}-U \\
\text { "di } & \text { uat }
\end{array}
$$

Eq. (2A) - It is assumed that the probability distribution of the opportunity cost across the hectares is exponential (i.e. the likelihood of an opportunity cost decrease exponentially as soon as its valué increases). In this way, Eq. (2.2) becomes:

$$
\mathrm{umx}<1-\exp \quad-\max (0, \mathrm{Pu})
$$

where aoc is the average opportunity cost. The $\max (-)$ function assures that the minimum number of target hectares is zero.

Eq. (3A) - Agricultural production in each hectare is negatively affected by significant losses of soil. Without such losses, the average production is constant and optimum in an economic sense. This means that the demand for capital is at the steady state valué needed to maximize profits per hectare. Suitability of natural resources (i.e. rainfall) is assured. Thus, the average production per hectare is given by

$$
\mathrm{Qu}=\mathrm{qop}^{\wedge} 1-\exp \quad \begin{gathered}
-\max (0, \mathrm{~S}-\mathrm{smn}) \\
\mathrm{qsf}
\end{gathered}
$$

qop is the average profit-maximizing production per hectare, $\mathrm{S}$ is the volume of soil (pore space notincluded), smn is the minimum volume of soil needed to provide the necessary water storage capacity to sustain plant growth, and qsf is a form parameter. Thus, in case A, the limiting factor is soil: a modérate decrease in soil volume implies losses of crop productivity; a high decrease in soil, such that $\mathrm{S}<\mathrm{smn}$, makes production unfeasible.

Eq. (4A) - Given the assumed constancy of the average demand for capital and that there is no marketable demand for natural resources, the average variable cost function c(-) is constant and can be taken as included in the average fixed cost, fcu. It is also assumed that there is no measure to control erosión. Taking all this into account, profit per hectare is given by

$\mathrm{Pu}=\operatorname{prq} \mathrm{Qu}-\mathrm{fcu}$

Eqs. (5A)-(7A) - Clearly, Eqs. (2.5)-(2.7) are not needed under the assumptions explained so far.

Eq. (8A)-Soil characteristics are similar across the whole studied área. The volume of soil per hectare has the following rate of varia tion:

$\mathrm{dS}$
$\mathrm{dt}$ : bwr - lch - bse exp $\begin{aligned} & -\mathrm{Qu} \\ & \text { sef }\end{aligned}$

The first term, bwr, is the weathering rate of the bedrock, and the second, lch, corresponds to the leaching rate. The difference bwr - lch can be assumed constant under invariable weather conditions, a constant slope and the same kind of soil. The third term of Eq. (3.5) is the interrill erosion rate. Again, given the constancy in time and/or space of soil type, crop and agricultural work, slope gradient and rainfall amount/intensity, the erosion rate is only a function of the vegetation cover, which is merely assumed to be proportional to Qu. Erosión drops exponentially as the crop grows, following Elwell and Stocking (1976); the constant sef sets the form of this exponential relation and the bse parameter is the bare soil erosión rate $(\mathrm{Qu}=0)$. But erosión does not necessarily disappear when production is at its economically optimum valué $\mathrm{Qu}=\mathrm{qop}$. It is clear that this valué does not assure enough vegetal cover across the whole year for annual crops and for the whole cultivated área for woody crops. The erosión rate when production is optimal is emn =bseexp[-qop/sef]. Whether this minimum erosión rate will be positive or nuil depends on the valúes of qop and sef. 


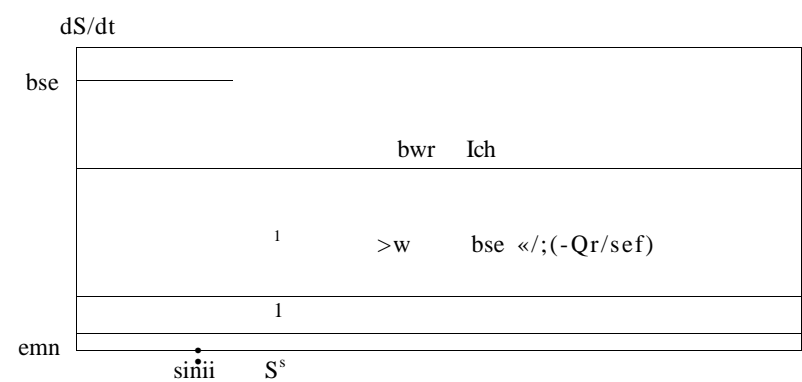

Fig. 1 - Soil equilibrium in case A when emn $<$ bwr - Ich $<$ bse.

To simplify the current application, we deliberately ignore erosión caused directly by agricultural work, which would be linked to $\mathrm{Ku}$, soil transfers between hectares and soil organic matter dynamics.

\subsection{Stability conditions-indicators of desertification risk}

The volume of soil is in equilibrium when $\mathrm{dS} / \mathrm{dt}=0$, which means that

bwr - Ich = bse exp $\begin{aligned} & -\mathrm{Qu} \\ & \text { sef }\end{aligned}$

Fig. 1 shows the generic form of both sides of this equation after substituting Qu by Eq. (3.3). In the illustrated case (which is just one of the possibilities, as explained below), the equilibrium volume of soil is ${ }^{1} \mathrm{~S}^{\mathrm{s}}$. The bwr-Ich valué represents the acceptable erosión rate (Kirkby, 1980).

This case admits three equilibrium conditions:

(A.l) bwr - Ich > bse. Under this unlikely condition there is no risk of desertification in the modelled system, because the soil grows endlessly and never becomes a limiting factor for crop productivity. In this way, both agricultural production per hectare and the number of cultivated hectares will, in the long run, reach steady states.

(A.2) emn<bwr-Ich<bse. This is the case illustrated in Fig. 1. The equilibrium value $S^{s}$ represents the threshold between the catastrophic lost of the whole volume of soil and its sustainable endless growth. Under the current conditions, the system is dependent on the initial valúes: agricultural production will be sustainable only if the initial volume of soil in a hectare is greater than $\mathrm{S}^{\mathrm{s}}$. The mathematical expression of this measure cannotbe solved, but it can be calculated by numerical iteration.

(A.3) bwr - Ich < emn. Given that the minimum erosión rate of the cultivated crops is greater than the net soil formation rate for every volume of soil, the long-term destiny of the system in this case is desertification.

${ }^{1}$ From now on, all superindexes name the respective state variable of an isocline. For example, $\mathrm{R}^{\mathrm{s}}$ is the isocline of $\mathrm{S}$, which is eventually solved for R.

\section{Case B: irrigated intensive agricultura] systems}

This case generically refers to a number of áreas in Spain characterized by an increasing colonization of irrigated crops. The relative low cost of water and the high demand for production leads to considerable profitability, which encourages the increase of the irrigated surface. The environmental consequences are aquifer overexploitation, sea water intrusión in coastal regions, soil degradation and salinization, river flow reductions and loss of wetlands (Ministry for the Environment, 2003, pp. 30-31).

\subsection{Model equations}

Another set of assumptions can be used to apply the model proposed in Section 2 to represent an ideal but likely instance compatible with the description given above.

Eq. (IB)-In Eq. (2.1) U is the number of irrigated hectares. In this way, Eq. (3.1) is also valid here.

Eq. (2B)-As in case A, an exponential probability distribution is assumed for the opportunity cost. In this way, Eq. (2.2) turns out to be equal to (3.2).

Eq. (3B)-The per hectare production function is

$\mathrm{Qu}=\mathrm{tch} \quad \mathrm{Ru}-0.5$ eqx

where $\mathrm{Ru}$ here is the average demand for water per hectare, tch is a technology-related parameter and eqx is the endowment of water allowing máximum production (i.e. $\mathrm{Q}^{\mathrm{T} \mathrm{M}^{\mathrm{ax}}}=0.5$ tch eqx). Note that endowments $\mathrm{Ru}$ greater than eqx imply decreasing yields per hectare. To simplify this application, it is assumed that the capital per hectare is constant and that there is no other production limiting factor.

Eq. (4B)-Profit per hectare is given by

$\mathrm{Pu}=\operatorname{prq} \mathrm{Qu}-\mathrm{CRRU}-\mathrm{fcu}$

$C_{R}$ is the marginal cost of water. Its value increases as soon as the total stock of water for irriga tion R decreases. It is assumed that this stock of water is exclusively a groundwater aquifer. The relation between $\mathrm{CR}$ and the piezometric elevation $\mathrm{Z}$ can be assumed to be linear:

$\mathrm{CR}=\mathrm{crm}+\mathrm{ucz} \mathrm{Z}$

If, additionally, it is assumed that neither the área of the aquifer, aqa, ñor its storativity, str, varies with $\mathrm{Z}$, then

$$
\text { rmx - R }
$$

aqa str

where $\mathrm{rmx}$ is the máximum aquifer capacity, which corresponds with $\mathrm{Z}=0$. Then, after substituting Eq. (4.4) in Eq. (4.3):

$\mathrm{C}_{\mathrm{R}}=\mathrm{crm}+\begin{gathered}\mathrm{ucz}(\mathrm{rmx}-\mathrm{R}) \\ \text { aqa str }\end{gathered}$ 
Eq. (5B) - Given that the average capital demand is assumed to be constant, Eq. (2.5) is not needed here.

Eq. (6B)-It is easy to check that Eq. (2.6) now results in:

$\begin{array}{ccc}\frac{\mathrm{dRu}}{\mathrm{dt}} & \operatorname{prqtch}[1-(\mathrm{Ru} / \mathrm{eqx})] \mathrm{Y} & \mathrm{Ru} \\ \mathrm{CR} & \mathrm{rat}\end{array}$

Consider that farmers have no other water supply except for the aquifer.

Eq. (7B) - The rate of variation of the stock of water $R$ is

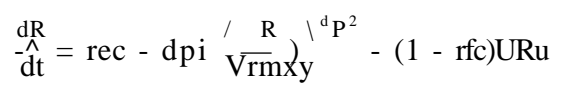

In this equation, rec is the average natural recharge of $\mathrm{R}$, which is assumed to be constant. The second term is the discharge rate, which would correspond exclusively to springs (Ibáñez et al., 2004). In such a term, dpi and dp2 are constants and $\mathrm{rmx}$ is the máximum aquifer capacity, as explained before. Finally, groundwater would not be used for anything but irrigation, where $\mathrm{rfc}$ is the return flow coefficient.

Note that, without pumps $(\mathrm{Ru}=0)$, the aquifer's natural equilibrium is achieved when $\operatorname{rec}=\operatorname{dpl}(\mathrm{R} / \mathrm{rmx})^{\mathrm{d}} \mathrm{P}^{2}$, that is to say:

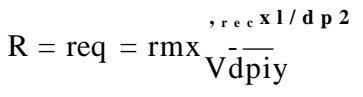

Additionally it is assumed that rec $<\mathrm{dpi}$, which means that req $<\mathrm{rmx}$. This circumvents having to define the discharge function for the completely full aquifer (for this formulation, see Ibáñez et al., 2004).

Eq. (8B)-To simplify the application showed here, it has been assumed that no limiting factor exists. After reading the initial description of case B, it is clear that the salt transported by water and accumulated in the soil could have played such a role.

\subsection{Stability conditions-indicators of desertification}

risk

The isocline of the per hectare demand for water $(\mathrm{dRu} / \mathrm{dt}=0)$ is

$\mathrm{R}^{\wedge \mathrm{u}}(\mathrm{R})=$ eqx $\quad 1 \quad \frac{\mathrm{CR}(\mathrm{R})}{\text { prq tch }}$

We will consider here only the case in which technical and economic conditions are good enough to assure a positive demand for even the last drop of groundwater. In this case, $\mathrm{CR}(\mathrm{R})$ should be less than prq tch for any valué of the stock R. This is assured if:

$\mathrm{C}_{\mathrm{R}}(0)=\mathrm{crm}+$ aqa str $\quad$ prq tch

$\mathrm{CR}(0)$ is the máximum marginal cost of water obtained after making $R=0$ in Eq. (4.5). Failure to consider condition (4.10) implies that there is some positive valué of $R$ at which the equilibrium demand for water disappears. This would mean that there is some technical or economic protection for groundwa-

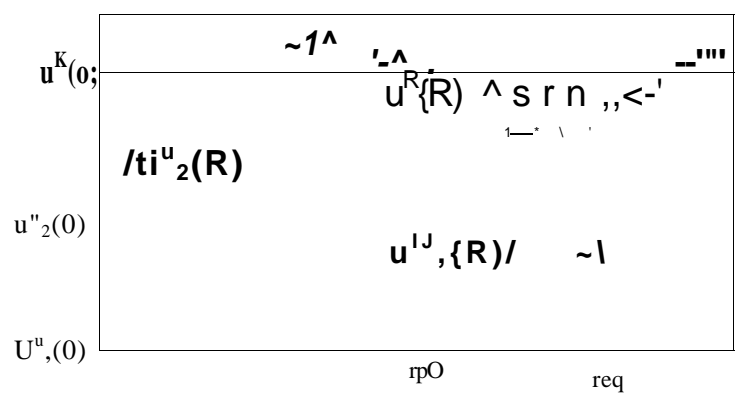

Fig. 2 - TWo possible groundwater stock and irrigated néctares equilibriums for case $B$ (each set of vectors of change is only valid for the nearest equilibrium).

ter and thereby no risk of it being overexploited.

The isocline of the stock $\mathrm{R}(\mathrm{dR} / \mathrm{dt}=0)$ can be expressed as

$\mathrm{U}^{\mathrm{R}}(\mathrm{R}, \mathrm{Ru}): \begin{gathered}\operatorname{rec}-\mathrm{dpl}(\mathrm{R} / \mathrm{rmx})^{\mathrm{dp} 2} \\ (1-\mathrm{rfc}) \mathrm{Ru}\end{gathered}$

This equation is always defined after assuming that $\mathrm{Ru}>0$ for any $\mathrm{R}$.

Finally, the isocline of the consumption units $(\mathrm{dU} / \mathrm{dt}=0)$ is

$\mathrm{U}^{\mathrm{U}}(\mathrm{R}, \mathrm{Ru})=\mathrm{U}^{\mathrm{D}}=\mathrm{umx} \lessdot 1-\exp \quad-\max (0, \mathrm{Pu}(\mathrm{R}, \mathrm{Ru}))$

The profit per hectare $\mathrm{Pu}$, which depends on $\mathrm{R}$ and $\mathrm{Ru}$, is expressed by Eq. (4.2).

Assuming that the adjustment time for water demand is quite a lot minor than the adjustment times for both groundwater stock and irrigated hectares, we adopt the quasi-steady state assumption (Edelstein-Keshet, 1988) that allows Ru to be represented by its equilibrium valué. Substituting the equilibrium condition (4.9) in (4.11) and (4.12) results in two functions of R: $U^{R}(R)$ and $U^{U}(R)$. Fig. 2 shows some examples of their generic form. Note that improving the technical and/or economic conditions of groundwater exploitation (for example, by increasing prq and/or tch) imply moving the curve $\mathrm{U}^{\mathrm{U}}(\mathrm{R})$ towards the upper left-hand córner. Thus, UÍ/R) in the illustrated example results from a better technical and economic parametric scenario than $\mathrm{U}^{\wedge}(\mathrm{R})$.

The outlined model of a competitively exploited aquifer can be seen as a special case of a predator-prey system, where, obviously, groundwater resembles the prey and the consumption units (i.e. irrigated hectares) are predators. It can be demonstrated (Ibáñez et al., 2004) that any intersection of $U^{R}(R)$ and $U^{U}(R)$ constitutes a steady state of the system given that they always satisfies the required conditions first established by Rosenzweig and MacArthur (1963).

Before setting all the possible long-term alternative states of the system a number of measures, only depending on parameters, need to be defined. Some have complex mathematical expressions, but all of them can be calculated by numerical iterations. These measures are: (i) the valúes $U^{R}(0)$ and $\mathrm{U}^{\mathrm{u}}(0)$ obtained after making $\mathrm{R}=0$ in $\mathrm{U}^{\mathrm{R}}(\mathrm{R})$ and $\mathrm{U}^{\mathrm{U}}(\mathrm{R})$, 
respectively (Fig. 2); (ii) the natural equilibrium of the aquifer req given in Eq. (4.8), which is the intersection point of $U^{R}(R)$ and the $\mathrm{U}=0$ axis; and (iii) the stock of groundwater $\mathrm{pO}$ under which the profit $\mathrm{Pu}$ is nuil, which matches the intersection point of $U^{\mathrm{U}}(\mathrm{R})$ and the $\mathrm{U}=0$ axis (Fig. 2). Note that this measure is equal to zero for curves of the type UÍ/(R).

In this way, the final states of the system for case B (after assuming condition (4.10)) are defined by

(B.1) rp0>req. Under this unlikely condition it will not be profitable to start up aquifer exploitation for agricultural irrigation. Therefore, the stock of groundwater will hold up on its natural equilibrium req.

(B.2) $0<\mathrm{rpO}<\mathrm{req}$. This condition corresponds to a curve of the type $U^{\wedge}(R)$ and necessarily to a non-nuil steady state of both the consumption units and the stock of groundwater (point A, Fig. 2).

(B.3) $\mathrm{rp} 0=0$ and $\mathrm{U}^{\mathrm{R}}(0)>\mathrm{U}^{\mathrm{u}}(0)$. The first of these conditions assures a positive profit even for the last drop of groundwater. However, given that $\mathrm{U}^{\mathrm{R}}(0)>\mathrm{U}^{\mathrm{u}}(0)$ is occurring simultaneously the system has a non-nuil long-term steady state (point B, Fig. 2).

(B.4) $\mathrm{rp} 0=0$ and $\mathrm{U}^{\mathrm{R}}(0)<\mathrm{U}^{\mathrm{u}}(0)$. Under these conditions, the aquifer will be completely depleted.

\section{Case C: commercial rangelands}

"Overgrazing is another classical agent of land desertification. The result is a decrease of the vegetation density/.../. If the slope is steep the resulting erosion processes appear" (Ministry for the Environment, 2003, p. 27). The incentives for livestock established by the CAP, especially sheep, could encourage farmers to overload their rangelands supplementing the animáis with feed. This problem affects or could affect extensive áreas of the Iberian Peninsula, including the dehesa, a savannah-like formation of permanent grasslands with disperse tree cover, which has a high ecological and environmental valué.

\subsection{Model equations}

$A$ new set of assumptions can be used to specify the equations outlined in Section 2 for the present case.

Eqs. (1C) and (2C)-In this case, the consumption units U should properly be the number of livestock herds ranging in an open access communal área, each herd owned by a single farmer. However, we will simplify this illustrative application by considering only what occurs in one hectare into such common área. This means that the dynamics of $U$ will be ignored in the following and also that the subindex $U$ here refers to one hectare.

Eq. (3C)-The per hectare production function is

$$
\mathrm{Qu}=\mathrm{qpkKu}
$$

The capital $\mathrm{Ku}$ is now the livestock numbers on the modelled hectare. It is a commercial single-species herd composed of breedingfemales with constant average physiological states and nutritional requirements. The hectare is covered by grass which is grazed by livestock at will; grass is therefore the natural resource $\mathrm{R}$ in case $\mathrm{C}$. However, the farmers add what supplementary feed is required to assure that both the productive and reproductive parameters of breeding animáis remain optimal and constant. In this way, the unitary production per female qpk can be considered constant. There is no limiting factor directly affecting livestock production.

Eq. (4C)-For simplicity's sake, supplementary feed only aims to satisfy the females' energy needs (i.e. protein and volume requirements are ignored). In this way, the per hectare variable cost function is

$\mathrm{c}(\mathrm{Ku}, \mathrm{Ru})\left\{\left(^{\wedge}\right) \max [0\right.$, uen-(f(R)gec $\left.)\right]+$ ouc $\mid \mathrm{Ku}=\mathrm{c}_{\mathrm{K}}(\mathrm{R}) \mathrm{Ku}$

where spr is the price of supplementary feed; cec is the energy content of concéntrate; uen is the energy requirements per animal; $/(\bullet)$ is the livestock functional response (i.e. grass consumption per animal), gec is the energy content of grass and ouc are other costs per breeding animal. The max(-) function assures that the minimum cost of the supplementary feed is zero. This will be achieved when grass satisfies all the animáis' energy requirements (i.e. $\mathrm{J}(\mathrm{R}) \mathrm{gec}>\mathrm{uen}$ ).

The functional response is given by

$/(\mathrm{R})=\mathrm{xca} \quad 1-\exp \quad \mathrm{R}$

where xca is the máximum consumption per animal; $R$ is the quantity of grass in the hectare and frf is a form parameter inversely related to animal intake efficiency in situations of low grass density. Note that total demand for grass in the modelled hectare is $\mathrm{Ru}=/(\mathrm{R}) \mathrm{Ku}$ -

The function $\mathrm{c}(\mathrm{Ku}, \mathrm{Ru})$ can be expressed as $\mathrm{c}_{\mathrm{K}}(\mathrm{R}) \mathrm{Ku}$, where $\mathrm{CK}(\mathrm{R})$ is the cost per breeding female which depends on the available quantity of grass. Therefore, the profit per hectare is

$\mathrm{Pu}=\operatorname{prq} \mathrm{Qu}-\mathrm{c}_{\mathrm{K}}(\mathrm{R}) \mathrm{Ku}-\mathrm{fcu}=\left[\mathrm{rpk}-\mathrm{c}_{\mathrm{K}}(\mathrm{R})\right] \mathrm{Ku}-\mathrm{fcu}$

where $\mathrm{rpk}=\mathrm{prq} q \mathrm{pk}$ is the return per breeding female.

Eq. (5C)-It is easy to check that, in the present case, Eq. (2.5) results in

$\begin{array}{ccc}\frac{\mathrm{dKu}}{\mathrm{dt}} & \mathrm{rpk} & \mathrm{Ku} \\ & *(\mathrm{R}) & \mathrm{ubi}\end{array}$

ubi is the useful breeding life of females. Note that this dynamic equation expresses a particular form of the wellknown Hardin's Tragedy of the Commons (Hardin, 1968): if there are any positive margin of profit per breeding female every farmer will be prompted to increase his/her herds because if he or she would not do, another one will do.

Eq. (6C)-As explained before, the demand for grass in the hectare is $\mathrm{Ru}=\mathrm{f}(\mathrm{R}) \mathrm{Ku}$, which rules out any partial adjustment scheme.

Eq. (7C) - The grass on which the livestock herd feeds is composed by a single perennial specie. Under this assumption and taking into account invariable average weather conditions, primary production of grass can be satisfactorily represented by means of the logistic function (Noy-Meir, 1975, 
1978). However, it is considered thatboth the intrinsic growth rate and the carrying capacity of grass are negatively affected by a significant reduction of the soil volume. On the other hand, the grass decay rate is proportional to its stock. Therefore, Eq. (2.7) results in

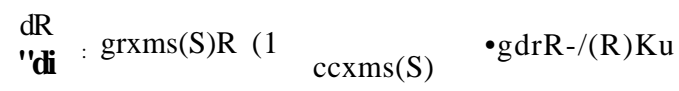

where grx is the máximum intrinsic growth rate of grass; ccx is the máximum carrying capacity, gdr is the grass decay rate and

$m s(S)=1-\exp \quad \max (0, \mathrm{~S}-\mathrm{smn})$

In this multiplier, smn is the minimum volume of soil needed for grass growth and gsf is a form parameter. Note that for a large volume of soil, $\mathrm{ms}(\mathrm{S})=1$ and grass productivity is unaffected. On the other hand, for small volumes of soil, $\mathrm{ms}(\mathrm{S})<1$ and grass productivity falls.

Eq. (8C) - The rate of variation of the soil volume is given by an equation similar to Eq. (3.5), where crop production $\mathrm{Qu}$ is now replaced by grass quantity $\mathrm{R}$ :

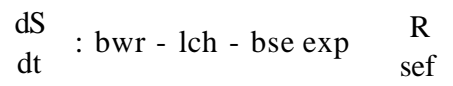

It has been assumed, for simplicity's sake, that the effects of the livestock herd on the soil erosión and organic matter rates are both negligible.

\subsection{Stability conditions - indicators of desertification}

risk

The isocline of the livestock numbers $(\mathrm{dKu} / \mathrm{dt}=0)$ is

${ }_{\mathrm{R}} \mathrm{Ku} \quad-\mathrm{frf}^{\prime} \ln \mathrm{1}+\frac{\text { rpkcec }- \text { spruen }- \text { ouccecl }}{\text { sprxcagec }}$

For this quantity of grass in the hectare, which only depends on parameter valúes, the farmers end their wish of growing up their herds. It implies getting a negative profit, assuming that the fixed cost fcu had to be financed anyway, but this is actually one of the meanings of the Hardin's tragedy in this particular case.

The soil isocline $(\mathrm{dS} / \mathrm{dt}=0)$ is

$$
\begin{aligned}
& \text {-sefln /bwr- lch } \\
& \mathrm{V} \text { bse }
\end{aligned}
$$

If $\mathrm{R}<\mathrm{R}$, erosión is greater than soil formation and, therefore, the final soil equilibrium is zero. If $\mathrm{R}>\mathrm{R}^{\mathrm{S}}$, erosión is minor than soil formation and soil would grow indefinitely.

Finally, it can be checked that the grass isocline $(\mathrm{dR} / \mathrm{dt}=0)$ results in

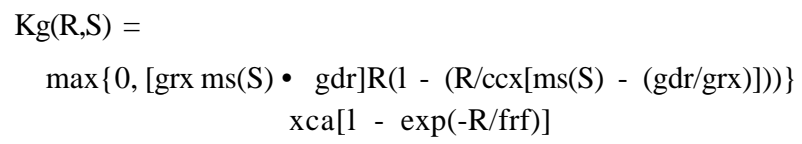

Fig. 3 shows the general form of this isocline. This has been sectioned by two planes, one for a high quantity of soil, such that $\operatorname{ms}(\mathrm{S}) \mathrm{R} ; 1$, and another for a lesser amount of soil, such thatms $(\mathrm{S})<1$.

Three aspects of the grass isocline or, more specifically, of the isocline sections for given quantities of soil deserve a special mention (demonstrations of RI.2 and RI.3 can be seen in Martínez Valderrama, 2005, Appendix III):

(RI.1) For any large quantity of soil (ms(S) R; 1, Fig. 3), the grass isocline section can always be considered the same.

(RI.2) A significant decrease in the volume of soil leads to a decrease in size and a shift to the left of the actual section of the grass isocline.

(RI.3) Let $\mathrm{R}^{\mathrm{M}}(\mathrm{S})$ be the quantity of grass corresponding to the máximum of the actual section of $K^{\wedge}(R, S)$ for a given valué of $S$. The máximum valué of $R^{\mathrm{M}}(\mathrm{S})$ is $\mathrm{R}^{\mathrm{M}}(\mathrm{oo})$ which is below the máximum of the section mentioned in RI.1. In accordance with RI.2, the positive (non-zero) valúes of $\mathrm{R}^{\mathrm{M}}(\mathrm{S})$ fall or tend to fall as the volume of soil $\mathrm{S}$ decreases. It is not easy to express $\mathrm{R}^{\mathrm{M}}(\mathrm{S})$ mathematically, but its numerical valué for any special case could be calculated by numerical iterations.

The equilibrium conditions in case $\mathrm{C}$ are described at length in Ibáñez et al. (2007) and Martínez Valderrama (2005). Only the main conclusions will be highlighted here.

\subsubsection{Equilibrium in case $\mathrm{C}$ urithout liuestock}

First, it is worth considering that $\mathrm{Ku}=0$. With this, the grass isocline becomes:

$\mathrm{R}^{\mathrm{R}}(\mathrm{S})=\mathrm{ccx} * \max$ jo, $\left.\quad m s(S)-(-) \quad\right)$

Then, if the volume of soil is high $(\mathrm{ms}(\mathrm{S})=1)$, the equilibrium valué of grass is constant:

$\begin{array}{ll}\mathrm{R}^{\mathrm{R}}(00): & \mathrm{gdr} \\ & \mathrm{grx}\end{array}$

Both the function $R^{R}(S)$ and the constant $R^{R}(o o)$ are shown in Fig. 3.

On the other hand, given that the soil isocline is independent of livestock numbers, it is still expressed by $\mathrm{R}=\mathrm{R}^{\mathrm{S}}$ (Eq. (5.10)).

The two likely combinations that can be established between the isoclines of the grass-soil subsystem without livestock are the result of placing $R^{\mathrm{s}}$ on both sides of $\mathrm{R}^{\mathrm{R}}(\mathrm{oo})$. Fig. 4 shows the two possibilities, as well as the subsystem trajectories for each región of the $(\mathrm{S}, \mathrm{R})$ phase plañe.

The conclusion is that if the corresponding parametric valúes were such that the condition $\mathrm{R}^{\mathrm{R}}(\mathrm{oo})<\mathrm{R}^{\mathrm{s}}$ held for the isolated grass-soil subsystem, or, alternatively, if the subsystem is or use to be (e.g., due to frequent and persistent droughts) at any point to the left of the separatrix represented in Fig. 4A, long-term desertification (i.e. loss of all grass and soil) would take place irrespective of whether or not there is any livestock. Under these circumstances, the presence of livestock would speed up the process of desertification. Overgraz- 


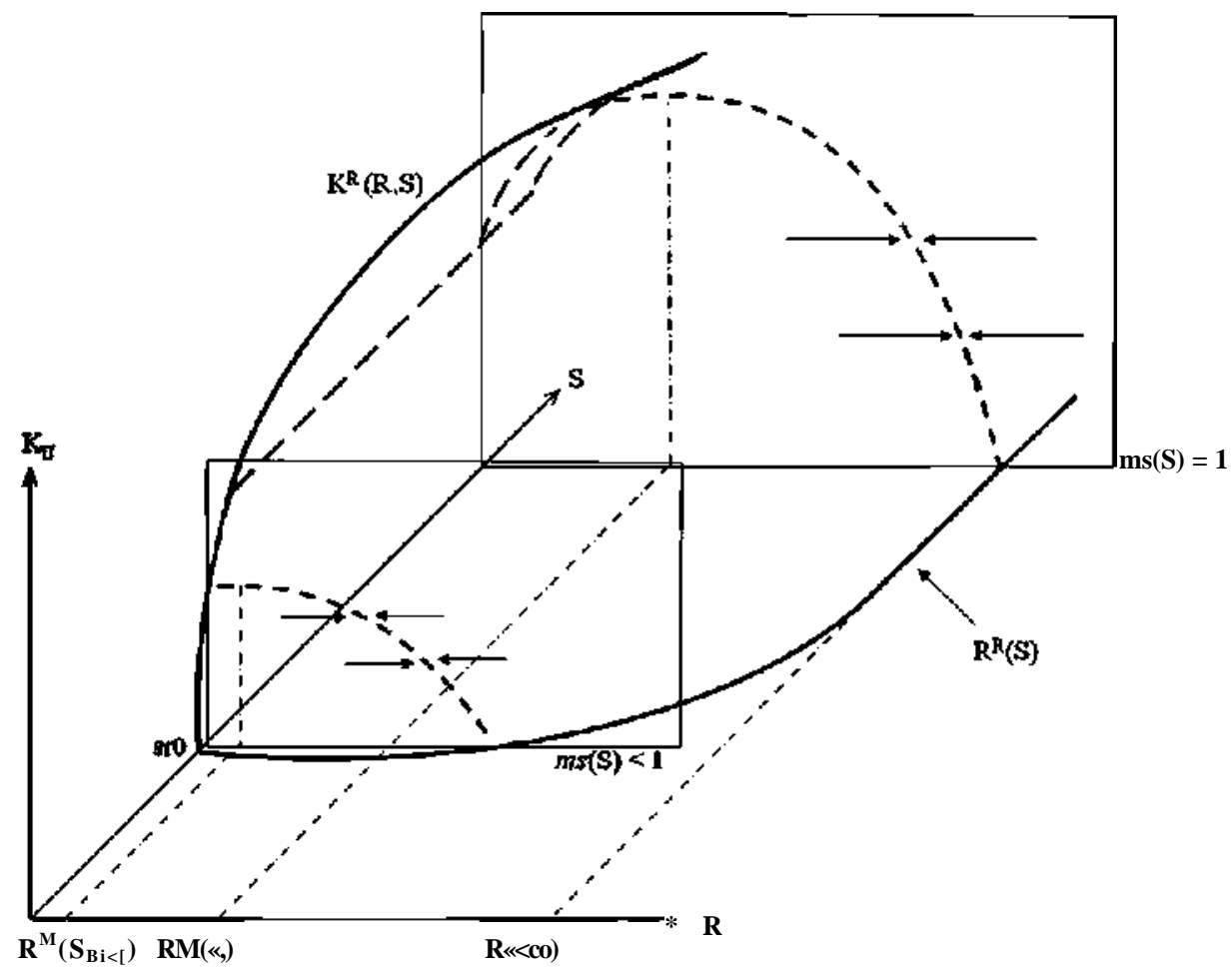

Fig. 3 - Grass isocline in case $\mathrm{C}$ with two sectíons, one for a large quantity of soil, ms(S) «* 1, and another for a small quantíty of soil, $\operatorname{ms}(\mathbf{S})<1$.

ing should, nevertheless, not be established as the cause of desertification.

\subsubsection{Equilibrium in case $\mathrm{C}$ ujith liuestock}

The analysis is confined to the following initial conditions, which, although implying some loss of generality, are particularly realistic and interesting in the case with which we are concerned: (i) at $\mathrm{t}=0$, an initial livestock number $K[i>0$ is entered into a grass-soil subsystem for which the condition $\mathrm{R}^{\mathrm{S}}<\mathrm{R}^{\mathrm{R}}(\mathrm{oo})$ holds; (ii) the original quantity of grass is $\mathrm{R}^{\mathrm{R}}(\mathrm{oo})$, corresponding with its stationary equilibrium without livestock (Eq. (5.13)); and (iii) the initial livestock number $K[i$ is modérate and reasonable in ecological terms.

Hypotheses (i) and (ii) imply that, initially, $\mathrm{ms}(\mathrm{S})=1$ and the volume of soil increases. With these two hypotheses, as discussed earlier, the grass-soil subsystem considered in the analysis would certainly not degrade on its own if there were no $K[i$. Accordingly, in those cases where the final equilibrium in the presence of livestock turns out to be desertification, we will be able to state that its cause is overgrazing. On the other hand, any área of grass can evidently be stripped in a short time if it is grazed by a disproportionate livestock herd; hypothesis (iii) serves to rule out this possibility from initial valúes.

The system's possible behaviours under the mentioned initial conditions derive from combining the relative positions of the quantities of grass $\mathrm{R}^{\mathrm{K}}$ " (Eq. (5.9)), $\mathrm{R}^{\mathrm{s}}$ (Eq. (5.10)) and $\mathrm{R}^{\mathrm{M}}(\mathrm{oo})$ (feature RI.3 of the grass isocline). Ignoring the very unlikely situations in which two or all three of these quantities could be equal, the following three basic criteria can be established to evalúate the risk of desertification due to overgrazing in the modelled system (Ibáñez et al., 2007; Martínez Valderrama, 2005):
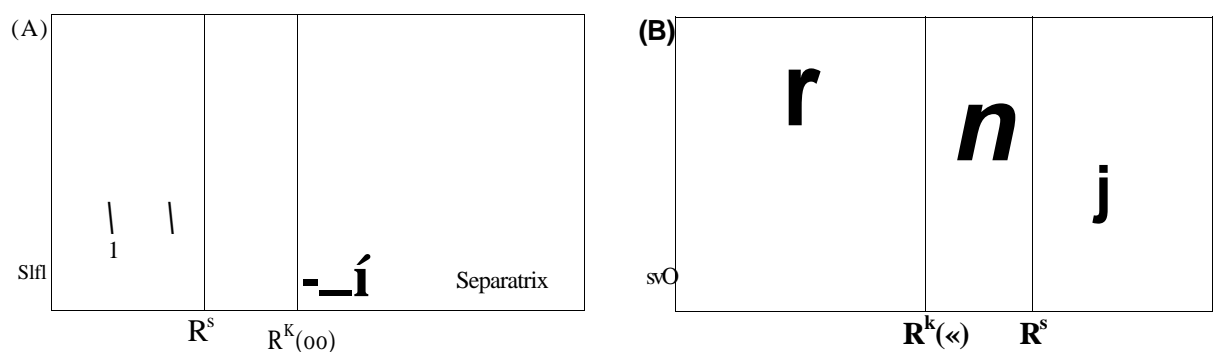

Fig. 4 - Long-term equilibriums and grass and soil trajectories without livestock $(\bullet)$ stable equilibrium and (O) unstable equilibrium. 
(C.l) $\mathrm{R}^{\mathrm{K}}>\mathrm{R}^{\mathrm{S}}$ and $\mathrm{R}^{\mathrm{K}}>\mathrm{R}^{\mathrm{M}}(\mathrm{oo})$. The risk of desertification is negligible.

(C.2) $\mathrm{R}^{\mathrm{K}}<\mathrm{R}^{\mathrm{S}}$. The system will desertify in the long term.

(C.3) $\mathrm{R}^{\mathrm{s}}<\mathrm{R}^{\mathrm{Ku}}<\mathrm{R}^{\mathrm{M}}(\mathrm{oo})$. The system runs a serious risk of desertification. In any case, if its long-term behaviour were to be sustainable, the system would be highly unstable.

\section{Discussion}

"Ecological economics is a transdisciplinary effort to link the natural and social sciences broadly, and especially ecology and economics" (Costanza, 1996). In this paper this intention becomes reality in a set of eight equations that relates natural resources dynamics with processes founded on economic decisions. What is more, the isocline's analysis has been used to catch the economic weight on equilibrium states, widening previous works that brilliantly carried with the ecological dimensión of the involved systems (Noy-Meir, 1975, 1978; Thornes, 1990). It is not easy to currently find in the ecological modelling litera ture papers dealing with a holistic point of view about the relations between ecology and economics in a conceptual or theoretical basis. It is easy to find models which include matters of different disciplines, but these are frequently detailed and big process-based models. The model presented here tries to help in understanding the essence of the overall ecological and economic processes involved in desertification. For this, an effort has been made to select the most important relations, so ignoring a large amount of detail. This tries to reinforce the pedagogical side of models, a function which should always play a complementary role to its important practical or applied side.

This paper is concerned with exploring an alternative approach for assessing the risk of desertification in threatened áreas. The procedure focuses on structurally driven desertification, meaning for that desertification which appears as a possible long-term state in human-resource systems evolving under constant average climatic and economic scenarios, i.e. desertification not specifically caused by changes in any of the senses reviewed by De Angelis and Waterhouse (1987). The procedure relies on a generic system dynamics model that can be applied to different desertification syndromes. For all the applications, interest focuses on finding all the possible longterm final states of the system and on defining the conditions that mark out sustainability and long-term desertification by means of specific parameter relations.

The system has been applied to three typified desertification syndromes in Spain: (A) rainfed crops in áreas with high soil erosión risk; (B) irrigated intensive agricultural systems which could cause processes like aquifer overexploitation or soil salinization; and (C) commercial rangelands threatened by overgrazing. Each application has used highly accepted partial models in order to increase the reliability of the results.

In case $\mathrm{A}$, assuming that no measures are taken to mitígate erosión, long-term sustainability is constrained in practice to the existence of a given high initial quantity of soil in áreas where average soil formation is greater than average minimum soil erosión. In this way, rather than determining an alternative state for this kind of systems, economic parameters would establish the total extension of land affected by the final state. For example, very high initial profits per hectare can cause the respective crop to quickly colonize all the suitable área long before losses of productivity due to erosión become significant. In such a case, if the final state is desertification, it could affect the total área.

On the contrary, in cases B and C, crop or livestock production profitability and technology are the only factors determining the thresholds between sustainability and longterm desertification given a definite stock of water with an average constant renewal rate in case $\mathrm{B}$ and given a rangeland with specific grass and livestock species farmed on a particular soil type with an average constant slope and under average constant weather conditions in case $\mathrm{C}$.

Both cases show that high profit scenarios are able to determine final states of desertification for a human-resource system seeking short-term profit maximization in spite of the assumption of constant average environmental conditions.

This could actually be the case of some communal dehesas in south-western Spain. The measures that define thresholds in case $\mathrm{C}$ have been estimated for an ideal but likely instance of one such rangeland with the following results: $\mathrm{R}^{\mathrm{K}} \mathrm{u}=0.135, \mathrm{R}^{\mathrm{s}}=0.858$, and $\mathrm{R}^{\mathrm{M}}(\mathrm{oo})=0.932$ for cattle and $\mathrm{R}^{\mathrm{K}}=0.372, \mathrm{R}^{\mathrm{s}}=0.858$, and $\mathrm{R}^{\mathrm{M}}(\mathrm{oo})=0.99$ for sheep (Ibáñez et al., 2007; Martínez Valderrama, 2005). Therefore, both cases are subject to the critical condition $\mathrm{R}^{\mathrm{Ku}}<\mathrm{R}^{\mathrm{S}}$. Moreover, there is a significant distance separating $\mathrm{R}^{\mathrm{K}}$ " from the other two reference quantities, making it unlikely that parameter variability within a normal range could alter expectations.

Is in the aim of this paper to point out that this kind of results of the explained procedure alerts to a serious risk of desertification for the systems examined and of the need to implement specific monitoring and mitigation programmes.

\section{REFERENCES}

Boer, M., Puigdefabregas, ]., 2005. Assessment of dryland condition using spatial anomalies of vegetation Índex valúes. International Journal of Remote Sensing 26 (18), 4045^1065.

Costanza, R., 1996. Ecological economics: reintegrating the study of humans and nature. Ecological Applications 6 (4), 978-990.

De Angelis, D.L., Waterhouse, J.C., 1987. Equilibrium and non-equilibrium concepts in ecological models. Ecological Monographs 57 (1), 1-21.

Edelstein-Keshet, L., 1988. Mathematical Models in Biology. McGraw-Hill, New York.

Elwell, HA., Stocking, M.A., 1976. Vegetal cover to estímate soil erosión hazard in Rhodesia. Geoderma 15, 61-70.

Geist, H., 2005. The causes and progression of desertification. In: Ashgate Studies in Environmental Policy and Practice. Ashgate Publishing Ltd.

GLASOD, 1990. Global Assessment of Soil Degradation. UNEP and ISRIC in cooperation with Winand Staring Centre, ISSS, FAO and ITC.

Hardin, G, 1968. The tragedy of the commons. Science 162 (13), 1243-1247.

Ibáñez, ]., Martínez, S., Martínez, ]., 2004. Competitive and optimal control strategies for groundwater pumping by agricultural production units. Water Resources Research 40, W03402.

Ibáñez, ]., Martínez, ]., Schnabel, S., 2007. Desertification due to overgrazing in a dynamic commercial livestock-grass-soil system. Ecological Modelling 205, 277-288. 
Kirkby, M.J., 1980. The problem. In: Kirkby, M.J., Morgan, R.P.C. (Eds.), Soil Erosión. John Wiley and Sons, p. 312.

LADA, 2002. Land Degradation Assessment in Drylands. Available at: http://lada.virtualcentre.org.

Martínez Valderrama, J., 2005. Estudio de la desertificación por sobrepastoreo mediante un modelo de simulación dinámica. $\mathrm{PhD}$ dissertation. Madrid.

Ministry for the Environment, 2003. National Program of Action against Desertification. Working Paper. Secretaría General de Medio Ambiente, Madrid.

Noy-Meir, I., 1975. Stability on grazing systems: an application of predator-prey graphs. Journal of Ecology 63, 459-481.

Noy-Meir, I., 1978. Stability in simple grazing models: effects of explicit functions. Journal of Theoretical Biology 71, 347-380.

Pickup, G., Stafford-Smith, D.M., 1993. Problems, prospects and procedures for assessing the sustainability of pastoral land management in arid Australia. Journal of Biogeography 20 (5), $471^{\wedge} 87$.

Prince, S.D. 2002. Spatial and temporal scales for detection of desertification. In: Reynolds, J.F., Stafford Smith, D.M. (Eds.), Global Desertification, Do Humans cause Deserts? Dahlem Workshop Report 88. Dahlem University Press.

Puigdefabregas, J., 1995. Desertification: stress beyond resilience, exploring a unifying process structure. Ambio 24 (5), 311-313.

Puigdefabregas, J., 1998. Ecological impacts of global change on drylands and their implications on desertification. Land Degradation and Rehabilitation 9, 393^06.
Regev, U., Gutiérrez, A.P., Schreiber, S.J., Zilberman, D.Z., 1998. Biological and economic foundations of renewable resource exploitation. Ecological Economics 26 227-242.

Rosenzweig, M.L., MacArthur, R.H., 1963. Graphical representation and stability conditions of predator-prey interactions. The American Naturalist 97 (895), 209-223.

Stafford-Smith, D.M., Reynolds, J.F., 2002. The Dahlem desertification paradigm: a new approach to an oíd problem. In: Reynolds, J.F. Stafford Smith, D.M. (Eds.), Global Desertification, Do Humans cause Deserts? Dahlem Workshop Report 88. Dahlem University Press.

Sterman, 2000. Business Dynamics. Irwin MacGraw Hill, Boston. The Millennium Ecosystem Assessment Series Synthesis Reports. Ecosystems and Human Well-being: Desertification Synthesis. 2005, available at: http://MAweb.org.

Thornes, J.B., 1990. The interaction of erosional and vegetational dynamics in land degradation: spatial outcomes. In: Thornes, J.B. (Ed.), Vegetation and Erosión: Processes and Environments. John Wiley \& Sons, Chichester, pp. 1-53.

UNCCD, 1998. United Nations Convention to Combat Desertification in Countries Experiencing Serious Drought and/or Desertification, Particularly in África. UNCCD Secretariat, Bonn, available at http://www.unccd.int. 